ANUARIO MUSICAL, N. ${ }^{\circ} 65$

enero-diciembre 2010, 251-268

ISSN: 0211-3538

\title{
EL ARCHIVO MUSICAL DEL CONVENTO FRANCISCANO DE CELAYA (MÉXICO)*
}

\author{
The Music Archive of the Franciscan Monastery in Celaya (MÉxico)
}

Lidia Guerberof Hahn

Archivo Musical de la Basílica de Guadalupe, México

\begin{abstract}
Resumen:
El Archivo Musical del Convento Franciscano de la Provincia de San Pedro y San Pablo situado en la ciudad de Celaya del estado de Guanajuato (México), contiene especialmente obras del siglo XIX, tanto de autores de la región como europeos. Tanto sus fondos documentales, como los del Archivo Histórico, sobrevivieron a la ocupación del ejército en 1859, en el marco de la Guerra de Reforma, o "de los Tres Años", entre liberales y conservadores, que finalizó con la victoria de los primeros y la entrada en la capital del país de Benito Juárez.
\end{abstract}

\section{Palabras Clave:}

Música; archivo musical; Celaya; México; Convento Franciscano; patrimonio histórico; documentación,; siglo XIX.

\begin{abstract}
:
The music archive of the Franciscan monastery of the Province of Saint Peter and Saint Paul, in Celaya City, Guanajuato State, Mexico, specially preserves musical compositions of the 19th century, by local composers and European musicians as well. Its documentary holdings, and those of the Historic Archive too, survived to the occupation by the army in 1859, during the Reform War, a long struggle between Liberal and Conservative forces, which finished with the victory of the former and the election of Benito Juárez as a new President of the Republic in Mexico City.
\end{abstract}

Key Words:

Music; music archive; Celaya; Mexico; Franciscan monastery; historical heritage; documentation; 19th Century.

* Archivo en proceso de catalogación 


\section{UN POCO DE HISTORIA}

Bajío se le llama a una región que se sitúa en el centro de México y que abarca parte del territorio del Estado de Guanajuato, de Querétaro y de Michoacán.

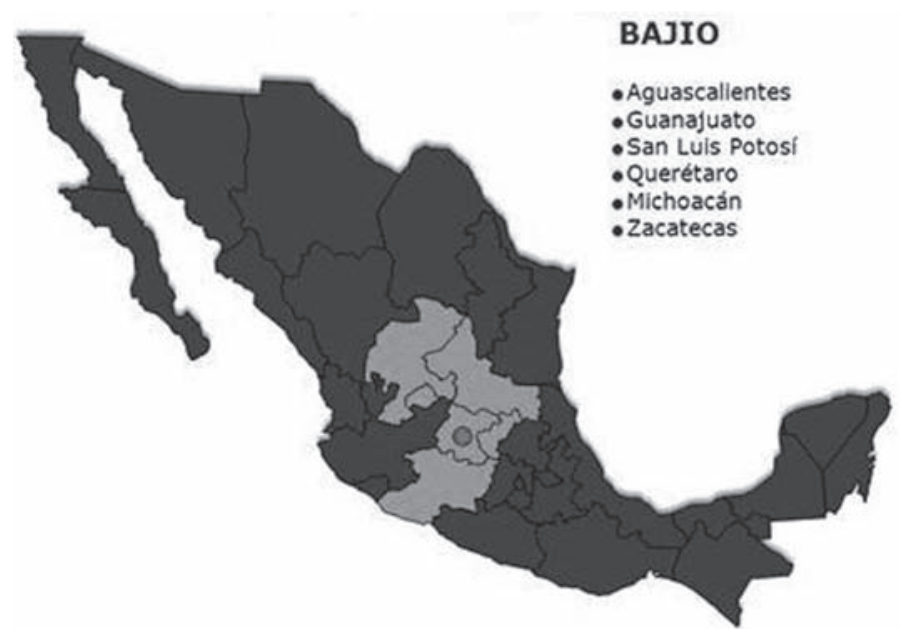

Figura 1. El bajío mexicano.

En esta región, habría que nombrar como las ciudades más pobladas a Celaya, Irapuato y León, todas ellas en el Estado de Guanajuato; Querétaro, en el estado de su nombre; y La Piedad, en el Estado de Michoacán.

Fueron tres los primeros frailes de la Orden Franciscana en llegar al Bajío en 1523, abriendo el camino para que un año después llegara el grupo llamado "Doce Apóstoles franciscanos" con la consigna de evangelizar los recién conquistados territorios. A ellos se sumaron posteriormente otros grupos que se organizaron en territorios provinciales.

La ciudad de Celaya estaba poblada, antes de su erección como tal, por un pueblo de la etnia otomí llamado "Nat-tha-hi”. Es el 12 de octubre de 1570 cuando a petición de un grupo de labradores vascos asentados en la zona y bajo el mandato del virrey español -leonés- Martín Enríquez de Almansa, se funda una nueva ciudad, bautizada como "Villa de la Purísima Concepción de Zalaya"1.

1 Zalaya, en idioma vasco (= "Zelaia") significa "tierra llana". Este es el nombre que figura en la información histórica, según la Historia de la Diócesis de Querétaro. 

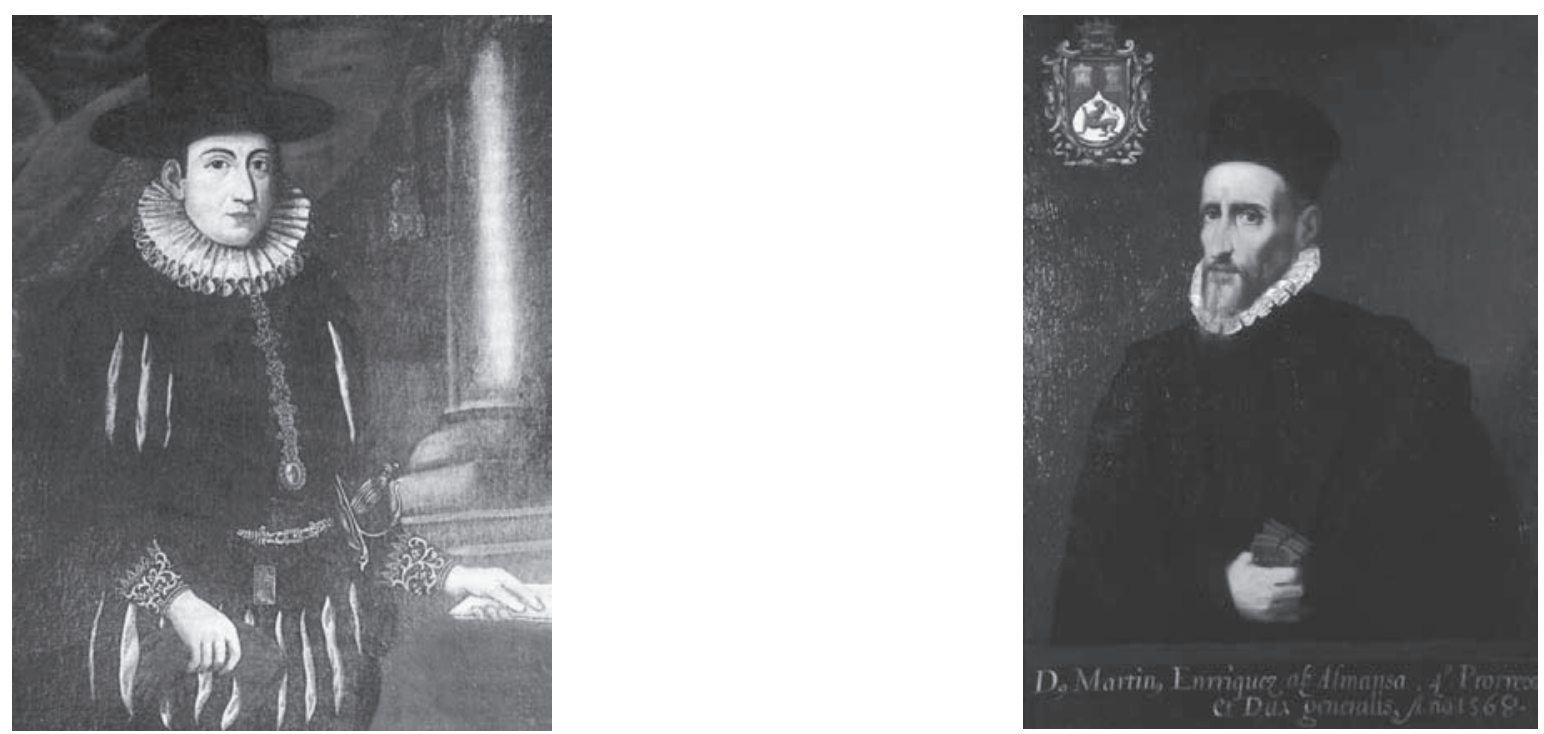

Figura 2. Dos imágenes del cuarto virrey de la Nueva España, Martín Enríquez de Almansa.

En el año de 1573, el mismo virrey Almansa da licencia para que la Orden Franciscana funde un monasterio en la mencionada ciudad y en 1668 el rey Felipe iv le concedió el titulo de "La muy Noble y Leal Ciudad de Celaya de la Purísima Concepción”, con escudo de armas propio en el cual figura la imagen de la Virgen.
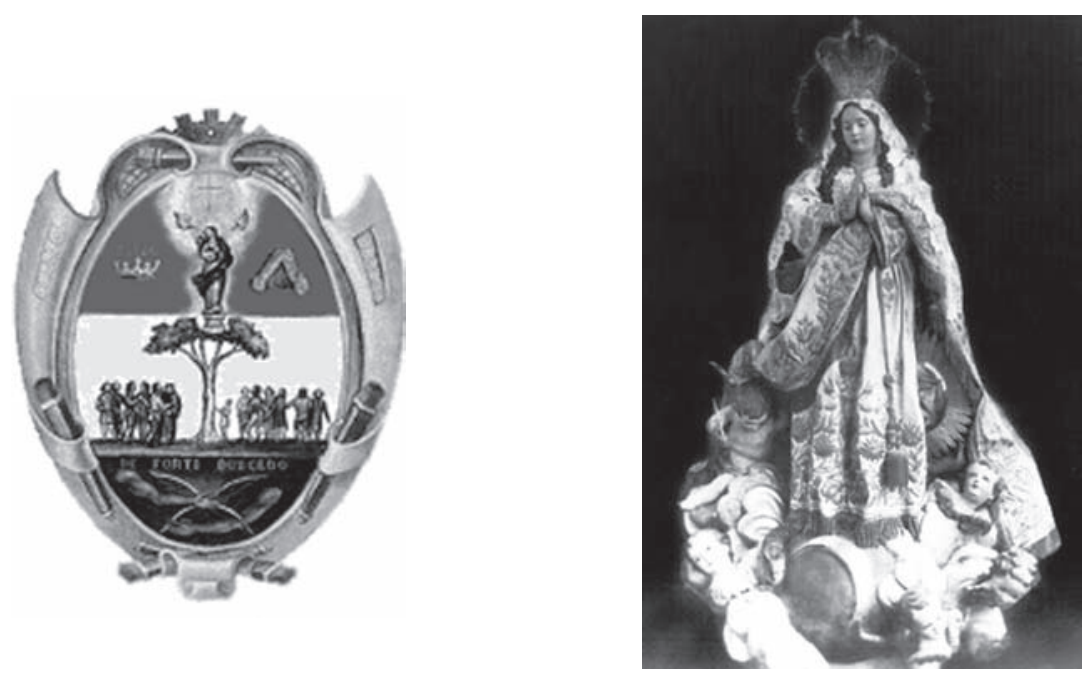

Figura 3. Escudo de la ciudad mexicana de Celaya, e imagen de su patrona. 
La ciudad de Celaya fue sede de alcaldía mayor en la jurisdicción del Gobierno y capitanía general de Nueva España y del obispado de Valladolid (hoy Morelia), Michoacán.

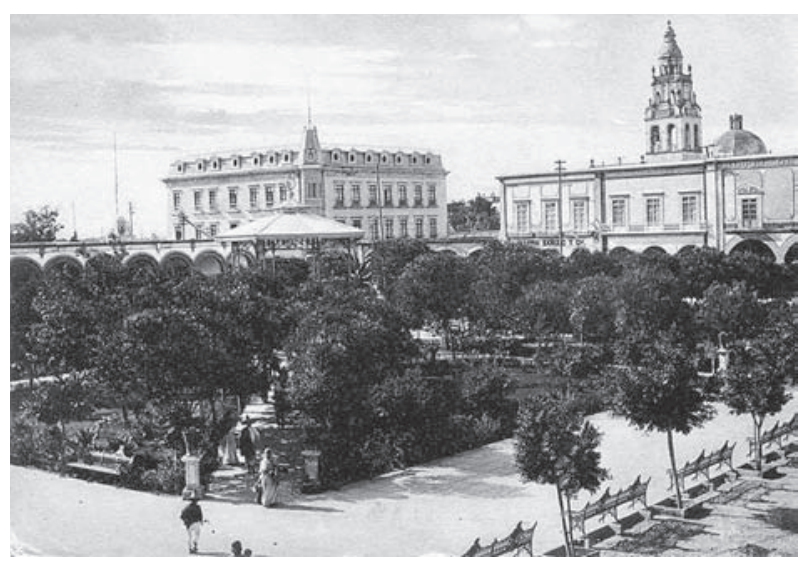

Figura 4. Plaza de Armas de Celaya, en el centro de la ciudad.

El Convento y Templo de San Francisco de Celaya es uno de los más grandes del país. Luce un interior barroco del siglo XVII construido sobre la capilla original en 1683, habiendo sido reconstruida su fachada, en estilo neoclásico, entre los años 1810 y 1820 por el afamado arquitecto, pintor y escultor Francisco Eduardo Tresguerras. (*Celaya, 1759; †1833).

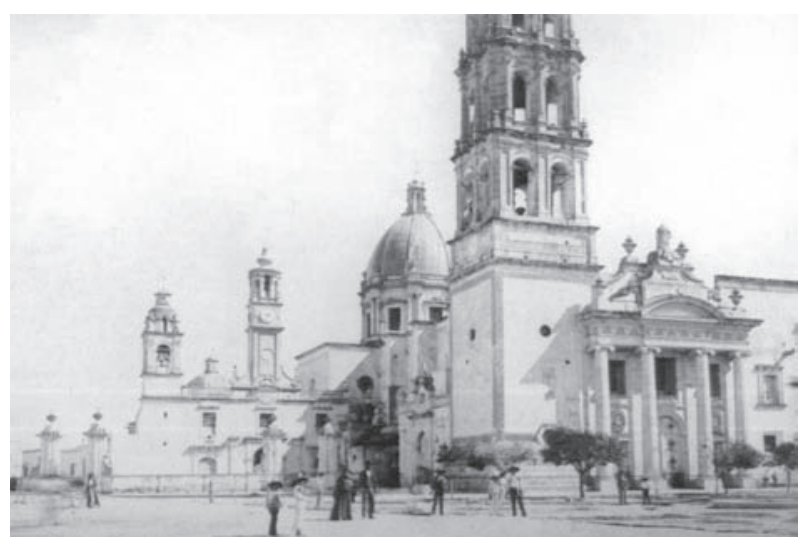

Figura 5. Una imagen antigua del Convento y Templo de San Francisco de Celaya, México.

La fachada del templo es de orden jónico, orientada al sur con cuatro grandes columnas que sostienen la cornisa. Una enorme torre de 64 metros; compuesta por tres cuerpos con dos arcos, se encuentra junto a la fachada. El conjunto del templo fue construido según el modelo de cruz latina, cuya dimensión más larga es de $66.5 \mathrm{mts} ., 11 \mathrm{mts}$. de ancho y $17 \mathrm{mts}$. de altura del suelo a las bóvedas. 


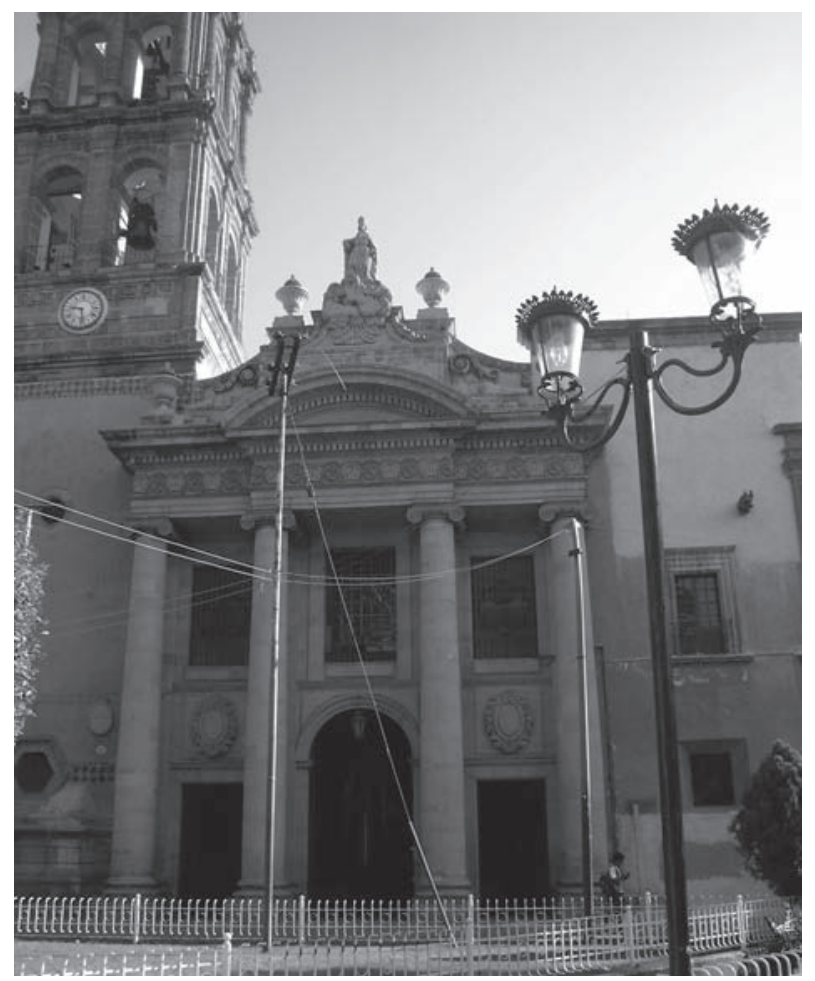

Figura 6. Aspecto actual de la fachada del Convento y Templo de San Francisco de Celaya, México.

En 1627 comenzó a funcionar el Colegio de la Purísima Concepción pasando a ser posteriormente Universidad Real y Pontificia con cátedras de Arte, Teología, Derecho, Retórica y Gramática.

En 1859, durante la Guerra de Reforma (1859-1861), parte del monasterio fue ocupado por tropas del ejército, que cambiaron la placa de la fachada del convento, "Collegium Universitatis", por la de "Cuartel Independencia", dejando a partir de entonces de existir el anterior Colegio. A diferencia de otros templos también tomados entonces por el ejército, y a pesar de la violencia posterior de las guerras padecidas ("Guerra Cristera"2 y "Guerra de Reforma"3, así como cien años de ocupación), aunque el edificio quedó

2 La llamada "Guerra Cristera" (o "cristiada", o "guerra de los cristeros") se desarrolló en México entre 1926 y 1929 , cuando grupos rebeldes (milicias de seglares y presbíteros católicos) se levantaron, al grito de "¡Viva Cristo Rey!", contra la legislación pública del gobierno de Plutarco Elías Calles, que restringió la actividad religiosa. Fue un enfrentamiento armado muy violento. (Cfr.: MeYer, Jean André: La Cristiada. 1. La guerra de los cristeros. México D.F., Siglo XXI, 1973. ID.: La Cristiada. 2. El conflicto entre la Iglesia y el Estado, 1926-1929. Ibídem, 1980. -ID.: La Cristiada. 3. Los cristeros. Ibídem, 1979).

3 La Guerra de Reforma, o "Guerra de los Tres Años" (17.12.1857-01.01.1861), enfrentó a Conservadores y Liberales, finalizando con el triunfo de estos últimos y la entrada de Benito Juárez en la capital del país. El gobierno resultante, presidido por Juárez, proclamó la separación de Iglesia y Estado, abolió las órdenes monásticas y confiscó las propiedades eclesiásticas. (Vid.: Galindo y Galindo, Miguel: Historia de México. La gran década nacional, o relación histórica de la guerra de reforma, intervención extranjera y gobierno del Archiduque Maximiliano, 1857-1867. México D.F., Oficina Tipográfica de la Secretaría de Fomento, 1904-1906; reed., México D.F., Fondo de Cultura Económica, 1987). 
muy maltrecho y en parte destruido, ha podido conservar buena parte de su rico patrimonio históricoartístico, ya que una pequeña parte del Convento siguió habitada por algunos frailes. Durante esos años, el Templo permaneció abierto y en funcionamiento como tal, hasta que, en 1950, el monasterio fue devuelto a la comunidad franciscana por el gobierno de Miguel Alemán. En el Coro del templo se encuentra un órgano, que acaba de cumplir cien años, en el cual se ofrecen conciertos con bastante frecuencia.
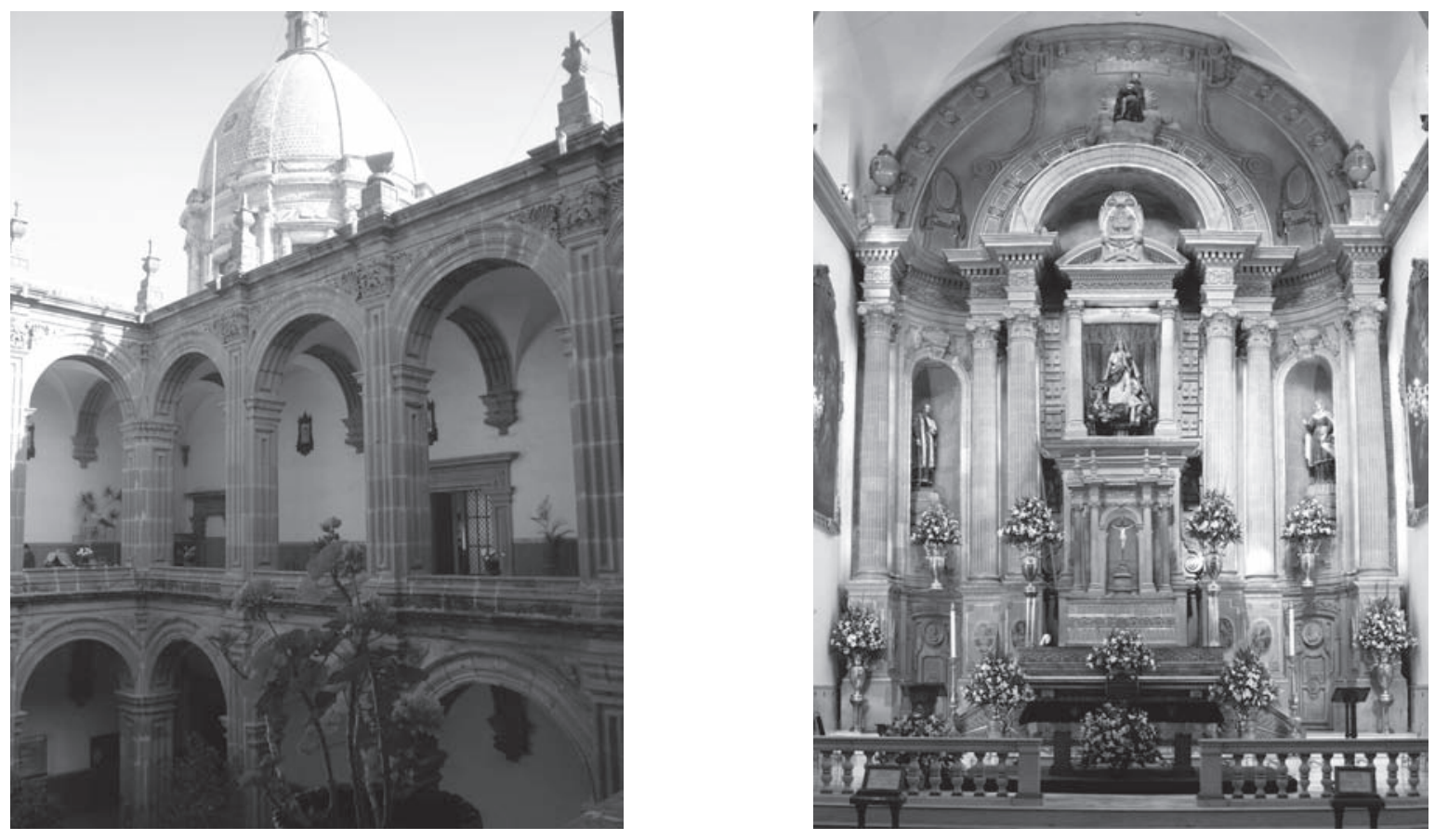

Figura 7. Convento y Templo de San Francisco de Celaya, México. Claustro, y altar mayor de la iglesia.

En el interior del convento se encuentra la valiosa Biblioteca antigua, el Archivo Histórico Provincial y desde hace poco tiempo, el Archivo Musical en formación.

Cuando se habla de Archivo Musical, nos estamos refiriendo a un gran archivo, incrementado con las partituras traídas del Convento Franciscano de la Santa Cruz de Querétaro, donde también se encuentra el Templo y la Universidad Franciscana de Filosofía. Evidentemente, la música era parte muy importante de la vida de los frailes de la provincia franciscana de San Pedro y San Pablo, que abarca los templos franciscanos de los territorios de Guanajuato, Michoacán y Querétaro, como se puede constatar al ver no sólo la gran cantidad de obras conservadas, sino también la calidad de las mismas. 

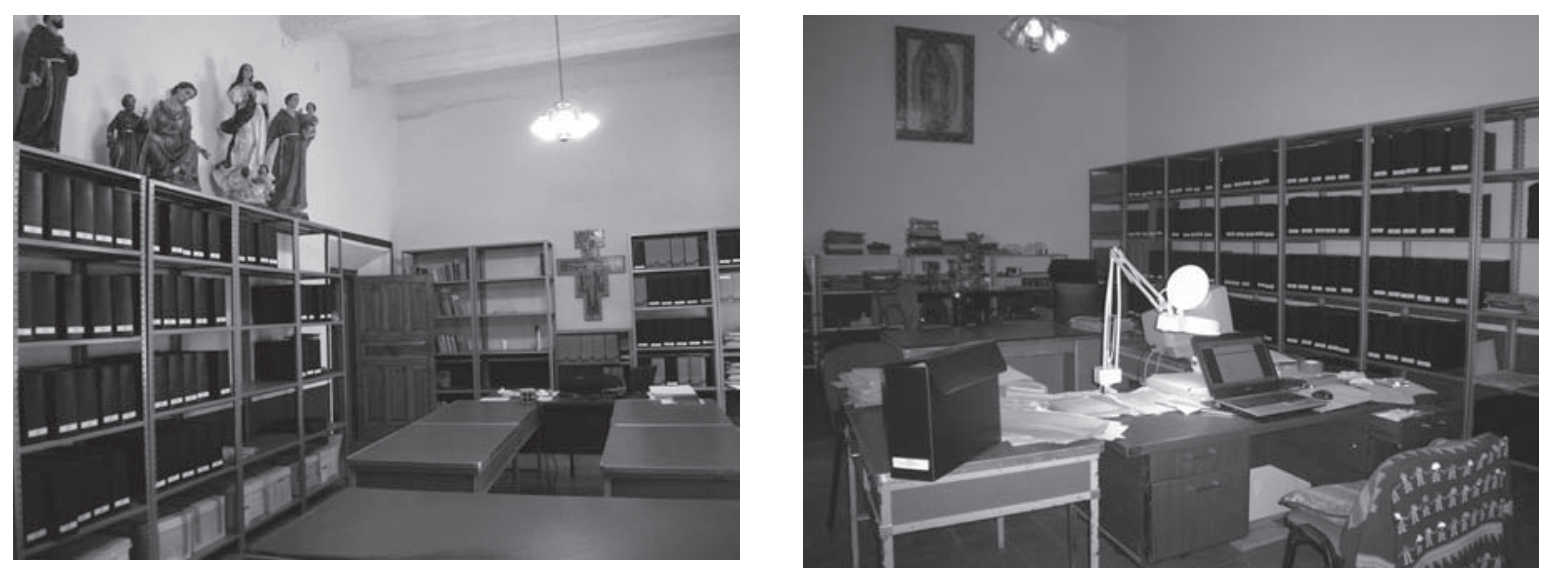

Figura 8. Dos aspectos del archivo de música del Convento de San Francisco, de Celaya (México).

Llama la atención la ausencia de manuscritos de los siglos XVII y XVIII presentes con relativa frecuencia en otros archivos catedralicios mexicanos; de éstos, sólo hay dos, pero lo interesante de su contenido es, en primer lugar, la gran cantidad de obras manuscritas y editadas de compositores de la región, poco conocidos en el ámbito musical del resto del país, cuando no completamente desconocidos. En segundo lugar, la presencia de abundantes ediciones del siglo XIX y comienzos del Xx de los grandes compositores europeos de música sacra, especialmente italianos, españoles y alemanes. La obra del inmortal J. S. Bach tanto religiosa como no (corales, misas, pasiones, toda la obra para clave y órgano), convive con las composiciones de Giovanni Pierluigi da Palestrina (*Palestrina, 1525c; †Roma 1594), Orlando di Lasso (*Mons, Hainaut, Bélgica, 1532; †Munich, 1594), o Tomás Luis de Victoria (*Ávila, 1548c; †Madrid, 1611), e incluso, ya de fechas mucho más cercanas, con la de Luigi Bordese (*Nápoles, 1815; †París, 1886), Luigi Bottazzo (*Presina di Piazzola, 1845; †Padua, 1924), Enrico Bossi (*Saló, Brescia, 1861; $\dagger$ En alta mar, 1925), Giovanni Pagella (*La Spezia, 1872; †Turín 1944), Giulio Bas (*Venecia, 1874; $†$ †énova, 1929), Lorenzo Perosi (*Tortona, 1872; †Roma, 1956), Franco Vittadini (*Pavía, 1884; †Pavía, 1948), Tomaso Gardella (*Carmogli, Génova, 1891; †1961c), Luigi Picchi (*Sairano, 1899; †Como, 1970), el franciscano padre Vicente Pérez Jorge (*Liria, Valencia, 1906; †Onteniente, Valencia, 1993), monseñor Domenico Bartolucci (*Borgo San Lorenzo, 1917), Tossi, Antonelli, P. M. Galletti, o Juan Alfonso García (*Los Santos de Maimona, Badajoz, 1935), sólo por mencionar a los más conocidos en copias manuscritas y diversas ediciones.

Algunas de las editoriales aquí más repetidas son las italianas Carrara (de Bérgamo), Marcelo Capra, y Leandro Chena (ambas, de Turín), Ricordi (italiana -de Milán-, y americana -de Buenos Aires-), Zanibon (de Padua), o la Asociación Santa Cecilia de Roma; las alemanas Schott (de Maguncia), Breitkopf \& Härtel (de Leipzig), Peters (también de Leipzig), A. Böhm (de Augsburgo) y Bärenreiter (de Kassel); las españolas Boileau y Bernasconi, Musical Emporium, y Subirana (las tres, de Barcelona), así como Ildefonso Alier, y Tesoro Sacro Musical (ambas, de Madrid); las mexicanas Otto y Arzoz (de México), Seminario Franciscano "Pio Mariano" (de Celaya, México), o Schola Cantorum, y Ediciones Franciscanas (de Celaya, México; 
Barcelona, España; y Asís, Italia); la francesa Alphonse Leduc (de París), la belga Desclée (de Tournai), o las estadounidenses Schirmer, y J. Fischer \& Bro. (de Nueva York); entre otras muchas.

También hay un gran número de compositores, especialmente italianos y españoles desconocidos, religiosos en general, cuyas obras probablemente llegaron a este lugar de la mano de otros religiosos que en algún momento estuvieron en alguno de esos dos países, enriqueciendo notablemente este fondo. Hasta ahora hay registrados 13.093 títulos -incluyendo en dicha cifra las composiciones musicales que aparecen en los libros-, que ocupan 135 cajas, aunque aún faltan obras por clasificar, aparte de toda una interesantísima música profana. En esa cantidad de títulos se incluyen también ediciones, que contienen de cien a quinientas obras aproximadamente de autores diversos.

Creo que dentro de tantos nombres sería más interesante darles un espacio primeramente a los compositores mexicanos que integran este archivo, si no a todos, sí al menos a los más representativos o que tuvieron un rol más importante, tanto en la región como en el país. No se tiene información hasta ahora si existió una capilla musical como tal en el Convento y Templo Franciscano de Celaya, aunque se conoce la existencia de un coro de infantes y adultos, -que fuera dirigido por el maestro compositor Isaías Barrón (*Cortázar, 1882; †Celaya, 1964)—4 ${ }^{4}$, así como de algunos otros organistas. Gracias a estos músicos, sin duda, se ha enriquecido el fondo musical del archivo.

Dado que este año se conmemoran con diversos conciertos y homenajes los cien años del nacimiento de Miguel Bernal Jiménez, tanto en su ciudad natal, Morelia, como en otros lugares del país, creo conveniente comenzar con algunos datos sobre este compositor. Nacido en Morelia, Michoacán en 1910, falleció en la ciudad de León, Guanajuato, en el año de 1956. Fue infante de coro de la catedral de Morelia, hasta que en 1928, una vez descubierto su talento, marchó a Roma a estudiar en el Instituto Pontificio de Música Sacra, graduándose en 1933 en Canto Gregoriano, Órgano y Composición, teniendo entre otros maestros a Licinio Réfice. Fue director de la Escuela Superior de Música Sacra de Morelia y fundador de la revista musical Schola Cantorum, en la cual publicaba, cada mes, artículos sobre diversos temas musicales, y en su suplemento, obras de no pocos compositores mexicanos, especialmente para órgano, y voz y órgano.

Fundó la Sociedad "Amigos de la Música" en 1938 y dirigió el Coro de los Niños Cantores de Morelia. La investigadora Lorena Díaz, autora del catálogo y biografía de este compositor, afirma que M. Bernal Jiménez, encabezó lo que se puede llamar el "nacionalismo sacro", como "consecuencia de un largo proceso que comenzó con el Motu Proprio de Pío x dado a conocer en noviembre de 1903"5.

El catálogo de este autor consta de 251 obras para órgano, orquesta, voces y órgano, coros, piano, cuartetos, el drama sinfónico Tata vasco, innumerables villancicos, etc.

En el archivo musical del Convento de San Francisco se encuentran varios villancicos, dos misas, motetes, unos Misterios, Réquiem, Siete Palabras, "Catedral" (23 piezas para órgano), una Sonata de Navidad y Sonata Sabatina -también para órgano-, así como algunas otras obras.

4 Compuso una Marcha a Celaya, y un conocido Himno al Mutualismo, y fue director de la banda Municipal de Celaya.

5 Díaz NúÑEz, Lorena: Miguel Bernal Jiménez, Catálogo y otras fuentes documentales. México D.F.-Morelia, Centro Nacional de Investigación, Documentación e Información Musical "Carlos Chávez" (CENIDIM) - Conservatorio de las Rosas, 2000 , p.12. 
El padre José Guadalupe Velázquez (*1856; †1920), formado musicalmente en Ratisbona, Alemania, funda en 1892 (junto con Agustín González) la Escuela de Música Sacra de Querétaro, con el fin de formar músicos y cantantes con una alta preparación para la música litúrgica. Compositor reconocido también en el ámbito europeo de la música sacra, se especializó paralelamente con gran talento en la dirección de coros.

El archivo musical del convento franciscano de Celaya cuenta con una Colección de Cánticos Guadalupanos, Cánticos Marianos, motetes, y otras obras como una Misa, un Popule meus, o un Vexilla Regis, entre otras obras de este compositor ${ }^{6}$.

El maestro Agustín González (*1864; †1927) fue otro de los muy reconocidos y apreciados compositores y organistas de la diócesis de Querétaro, que junto a Guadalupe Velázquez se dio a la tarea de formar músicos litúrgicos en la Escuela de Música Sacra.

El archivo musical de Celaya alberga una colección de 22 Cantos del iv Centenario de las Apariciones Guadalupanas, así como cinco Misas, un Misterio, Motete, Himno a Santa Cecilia, In solemnitate N. P. S. Francisci, y unos Maytines de la Purísima que tienen la siguiente inscripción:

"Compuesto para solemnizar el 50 Aniversario de la Inmaculada Concepción y para / ejecutarse en las Catedrales de México, Morelia, Guadalajara, Querétaro y Zamora y / en las Iglesias del Beaterio de Sn. Juan del Rio, Parroquia de Hércules, San Agustín, Santa Clara / Capuchinas de Querétaro. / Morelia del S. C., 26 de Noviembre de 1918".

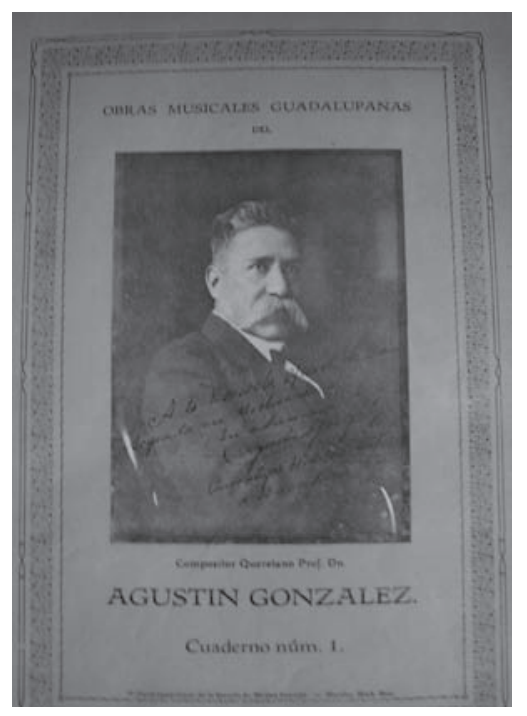

Figura 9. Una partitura del compositor y maestro Agustín González (*Santa Cruz de Galeana, Querétaro, México, 1864; †Quéretaro, México, 1927), con dedicatoria autógrafa, publicada en los Talleres Tipográficos de la "Escuela de Música Sagrada” de Morelia, en el Estado de Michoacán (México).

6 Cfr.: Sordo Sodi, Carmen: "Velázquez Pedraza, José Guadalupe", en Diccionario de la Música Española e Hispanoamericana. Vol. 10. Madrid, Sociedad General de Autores y Editores, 2002, p. 798. 
Este mismo maestro es autor también de un Panegírico a la Virgen María para 4 voces y gran orquesta, que se ejecuta cada año, el día 7 de diciembre por la noche, en el Templo del Convento de San Francisco de la ciudad de Celaya, "para recibir la Festividad de la Inmaculada Concepción”, el cual fue compuesto en 1908 "para la ceremonia de la coronación de la Inmaculada en Celaya"7.

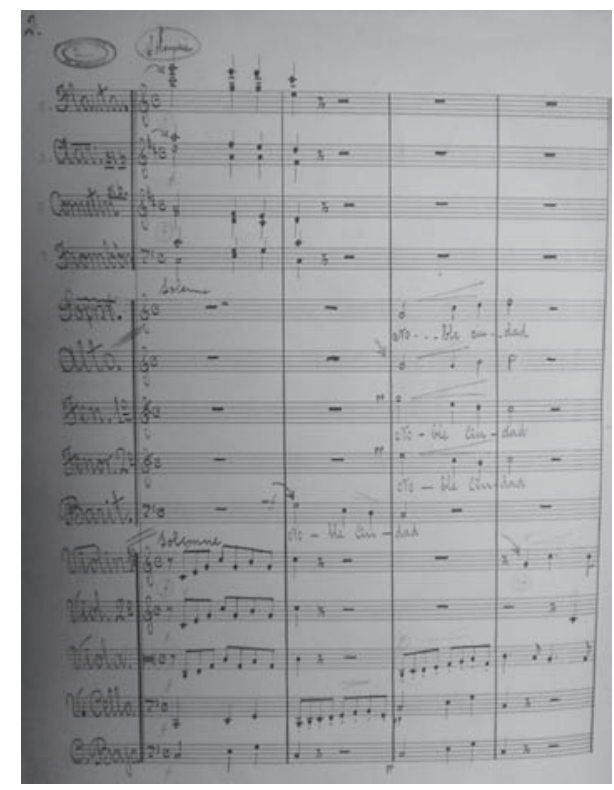

Figura 10. Panegírico, del maestro Agustín González.

Es imposible hablar aquí de todos los compositores cuyas obras integran este archivo, pero cabría mencionar a algunos de los más prolíficos y destacados como Delfino Madrigal Gil (*Erongarícuaro, 1924), que ha sido organista de la catedral de México y docente en la Escuela de Música Sacra y en el Conservatorio de las Rosas de Morelia; o a Domingo Lobato Bañales (*Morelia, Michoacán, 1920), formado como infante de coro de la catedral y en la escuela Superior de Música Sacra de Morelia, donde fuera discípulo de Bernal Jiménez, especializándose luego en Canto Gregoriano y Composición y obteniendo el Premio Jalisco 1958 por su labor como investigador de la música virreinal; a Francisco de Paula Lemus (autor de cientos de Misterios), o a Eduardo Loarca Castillo (*Querétaro, 1922; †2004) -cronista de la ciudad de Querétaro, director del conservatorio de dicha ciudad y prolífico escritor de arte e historia-, así como al padre Cirilo Conejo Roldán (*Querétaro, 1884; †1960), maestro de numerosos músicos mexicanos, alumno a su vez del padre Velázquez y fundador del Conservatorio de Música de Querétaro que actualmente funciona conjuntamente con la Escuela de Música Sacra; sin dejar de citar al menos a Mariano Paulín, organista

7 Véase: Sordo Sodi, Carmen: “González, Agustín”, en Diccionario de la Música Española e Hispanoamericana. Vol.5. Madrid, Sociedad General de Autores y Editores, 1999, p.738. 
del Templo Franciscano de Acámbaro (cercano a Celaya), del Templo de San Francisco de Celaya y otros circundantes; y al ya mencionado maestro Isaías Barrón, también organista y director del coro de este templo, fundador de la Sociedad Santa Cecilia y de una Academia de Música

No quisiera, terminar esta breve relación de compositores sin hablar de uno de ellos que ha merecido un espacio aparte en la catalogación del archivo. Me refiero a fray Serafín Ramírez, o.F.M. Nacido en 1888 en la ciudad de Zamora, Michoacán, con el nombre de Diego, sintió desde niño la vocación religiosa e ingresó en el Seminario Diocesano de esa ciudad, dejándolo en 1903 para entrar en el Colegio Pío Mariano de la Orden Franciscana en Querétaro, donde sería admitido en el Coro como tiple, iniciando el noviciado y cambiando luego su nombre por el de Serafín. A partir de 1904, estudió Filosofía y Teología, ejerciendo también como cantor y organista del Santuario del Pueblito (Querétaro). En 1909 inició sus estudios con el maestro Agustín González, y en 1913 fue ordenado sacerdote.

Ante la persecución religiosa acaecida entre 1926 y 1928, marchó a España junto con otros sacerdotes, y después de residir un tiempo en Barcelona, donde estudió con José Barberá en el Convento de San Antonio, se dirigió en 1928 a Roma, donde permaneció tres años dedicado al estudio de la música en el Instituto Pontificio de Música Sacra, graduándose en estética gregoriana, acompañamiento gregoriano, órgano y composición. Entre otros, tuvo como maestro a Rafael Casimiri. Regresó a México en 1930.

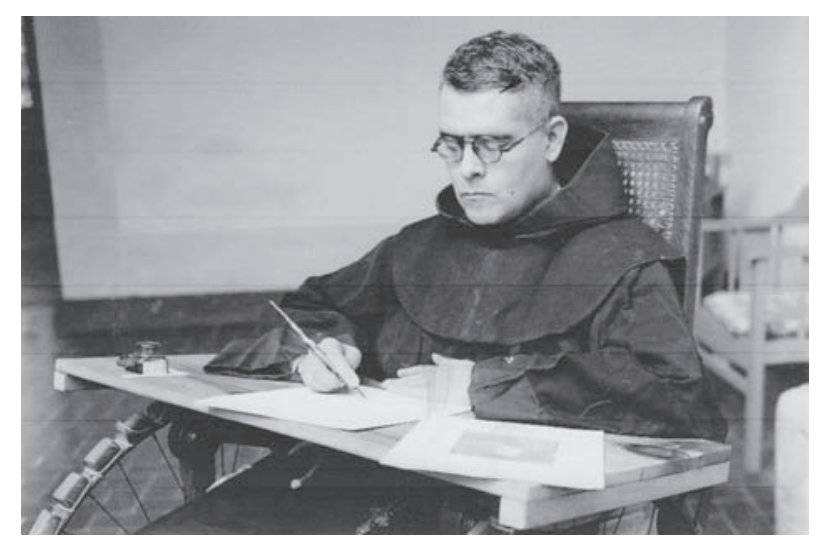

Figura 11. El monje franciscano, padre fray Serafín Ramírez $(* 1888 ; † 1962)$.

Poco a poco, su salud se vio mermada por una parálisis progresiva y por ceguera, que le impedía escribir, pero sin darse por vencido enseñó a escribir música a la señora que le atendía, dictándole sus composiciones.

Gracias a ello, se pudo conservar gran cantidad de obras, así como numerosos borradores, escritos sobre las reglas de la composición litúrgica, críticas, etc. etc. También fue editada parte de su obra por

8 Sobre alguno de estos autores, puede verse: Ortega, Judith: "Madrigal Gil, Delfino", en Diccionario de la Música Española e Hispanoamericana. Vol.7. Madrid, Sociedad General de Autores y Editores, 2000, p.28. -Sordo SodI, Carmen: "Loarca Castillo, Eduardo", ibídem, vol.6, p.972. EAdEM: "Conejo Roldán, Cirilo”, ibídem, vol.3, 1999, p.869. 
"Ediciones Franciscanas". Falleció en la ciudad de Celaya en 1962, a los 74 años de edad. Su producción musical solo terminó con su muerte9 .

Realizó un extraordinario arreglo de las Siete Palabras de Nuestro Señor Jesucristo, de Pedro. B. Falconara, para 4 voces mixtas y órgano. De este trabajo, la Comisión Diocesana de Música Sagrada de México comunica que sí puede editarse y que dicha Comisión:

"estima que es digna de admiración y alabanza la difícil labor que ha emprendido de dignificar, ajustándolas a los cánones del expresado Motu Proprio, composiciones que no se amoldan de suyo a las exigencias de la verdadera música sagrada". (Pbro. Cesáreo Munguía).

La obra está editada por la "Colección de Música Sacra - México, 1942”.

Por último, para tener una idea del nivel de análisis y juicio crítico de fray Serafín Ramírez, transcribo algún que otro fragmento de una crítica, dura por cierto, pero no por eso inaceptable sino todo lo contrario, sobre una obra que no se especifica, pero que parece ser las Siete Palabras:

“[...] por el lado armónico se descubre luego la falta de instrucción escolar, lo que origina el sinnúmero de errores en el uso de los acordes, se confirma aquello: Grande [es la] diferencia del músico que en sus obras lo guía una ciega [...roto...], al del compositor que escribe sus obras basado en los principios insustituibles del Arte [...]".

“[...] Es de desearse más sentimiento cristiano, más pureza de Arte y más apego a las sabias leyes de la Iglesia para una obra como esta". (Guadalajara, Jalisco II-8-1941 - Firmado: Fr. Serafín Ramírez, enfermo).
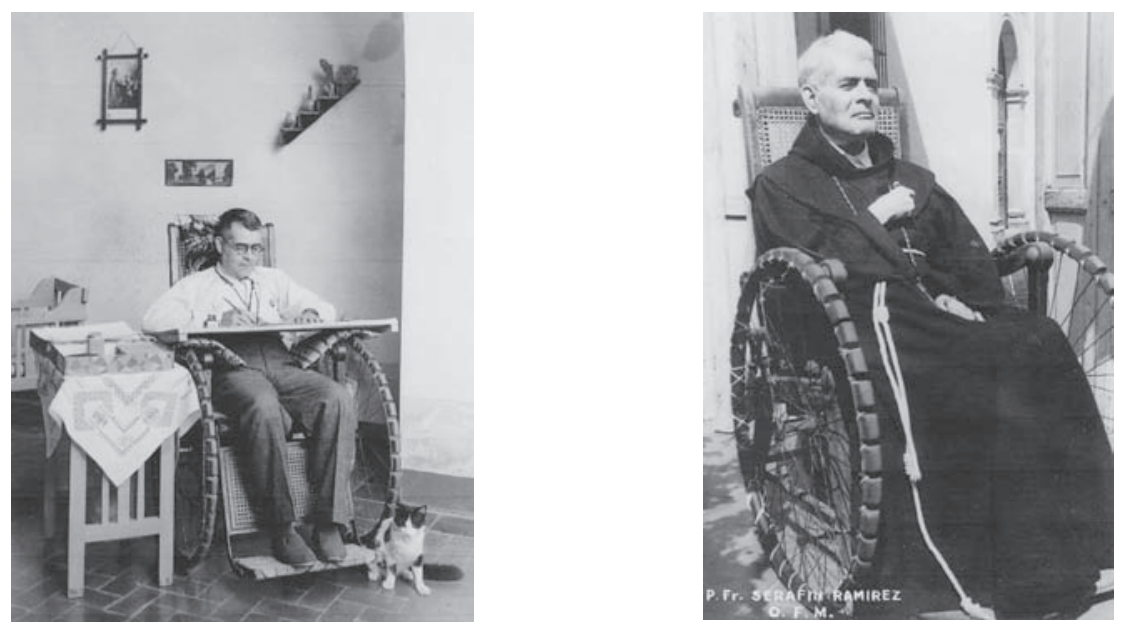

Figura 12. Dos imágenes del compositor mexicano, padre fray Serafín Ramírez $(* 1888 ; † 1962)$.

9 CAmpos, fray Leopoldo: Fray Serafín. Celaya (Guanajuato), Edic. Imprenta Franciscana, octubre de 1968, pp. 7-11. 
En el Archivo Musical del Convento de Celaya se conservan, entre otras obras varias, colecciones como son: 29 Cantos Josefinos, 33 Cantos al Salvador, 33 cantos a Jesucristo, 30 cantos a Cristo Rey, varias colecciones de Cantos Marianos (137), 58 Cantos Eucarísticos, 35 Cantos Populares, 31 Himnos, 55 Cantos Guadalupanos, Invitatorios, Misterios, Imitaciones Gregorianas, Fugas, arreglos y recopilaciones, e independientemente de estas obras editadas, se conservan también decenas de borradores de todo tipo, incluidos varios cuadernos con sus ejercicios de composición y polifonía realizados mientras estudiaba en Roma. En general, su música está escrita para voces y órgano, habiendo realizado arreglos de melodías populares.
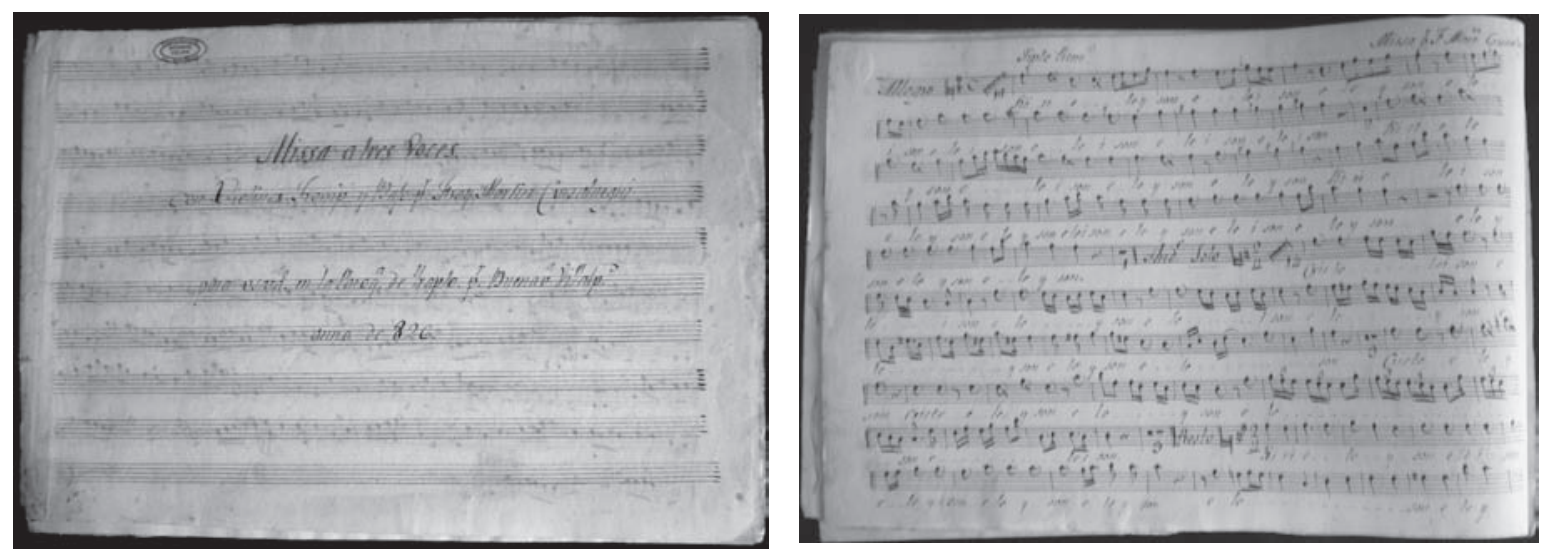

Figura 13. Dos imágenes de la Misa a 3, del compositor de origen vasco fray Martín de Crucelaegui, "para usar della en la Par[r]oq[ui]a de Yrap[ua]to p[o]r Buenav[entur]a Villalp[and]o / anno de [1]826”. Portada, y comienzo del Tiple Primero. Celaya (México).

En cuanto a los compositores españoles representados en este archivo, además de los mencionados al inicio del presente trabajo, quedan dos manuscritos de fray Martín Francisco de Crucelaegui (*Elgoibar, Guipúzcoa, 1737; †México?, 1784p $)^{10}$ : una Missa, a 3 voces con violines, trompas y bajo; y un himno a la Virgen María Sub tuum praesidium, a 4 voces con orquesta (siendo éstos los únicos manuscritos del siglo XVIII que se conservan en este archivo).

10 Sobre este autor, véase: BAgüÉs ERriondo, Jon: "Crucelaegui, Martín de", en Diccionario de la Música Española e Hispanoamericana. Vol.4. Madrid, Sociedad General de Autores y Editores, 1999, p.206. Guerberof HahN, Lidia: Insigne y Nacional Basílica de Santa María de Guadalupe. Archivo Musical. Catálogo. México D.F., Basílica de Guadalupe, 2006. -EAdEm: "El archivo de música de la Insigne y Nacional Basílica de Santa María de Guadalupe, de México", en Anuario Musical, 62 (2007), pp.257-269; cfr. especialmente, p.268. 


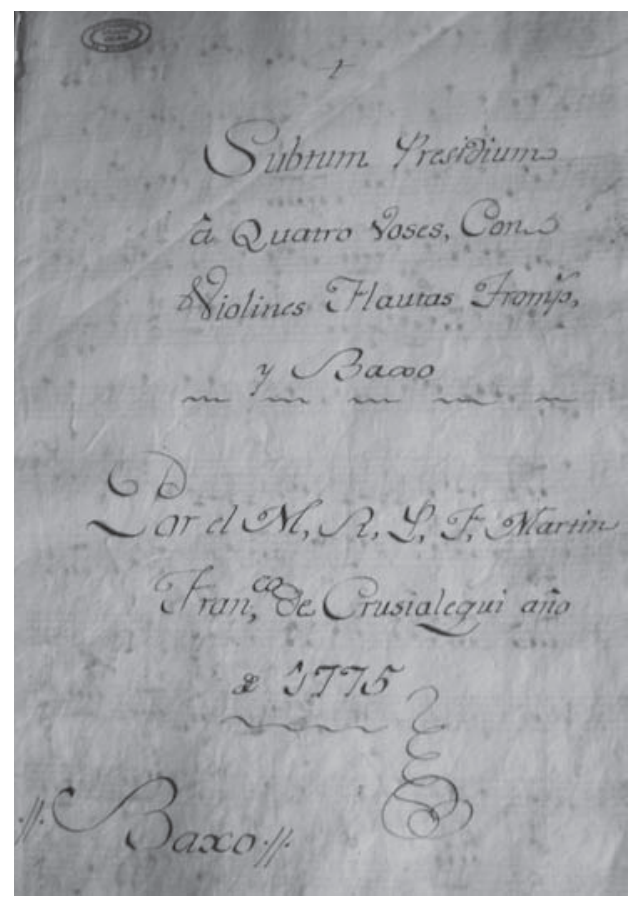

Figura 14. Portada de la parte del "Baxo", del himno Sub tuum praesidium, a 4 voces y orquesta, de fray Martín de Crucelaegui (1775).

Dos Misas del pbro. sacramentino vasco Martín Gorostidi Altuna (*Amezqueta, Guipúzcoa, 1913; $†$ †ilbao, Vizcaya, 1988) ${ }^{11}$, una obra de Ildefonso Ripollés, otra del Padre Donostia ${ }^{12}$, y del mercedario español fray Manuel Sancho, varias zarzuelas de contenido religioso ${ }^{13}$.

Para concluir este esbozo del contenido del archivo musical de Celaya, quisiera mencionar lo que me parece una joya musical, por su hallazgo en este lugar, por su calidad y belleza musical y por su singular construcción y desarrollo. Me refiero a las:

11 Véase: López-CALo, José: “Gorostidi, Martín”, en Diccionario de la Música Española e Hispanoamericana. Vol.5. Madrid, Sociedad General de Autores y Editores, 1999, p.794. Este autor, organista y compositor, se formó como discípulo de Eduardo Mocoroa y Luis Urteaga. Se ordenó en 1940, ampliando estudios en Madrid con Benito García de la Parra. Fundó la Escolanía del Santísimo Sacramento. Vivió algunos años en La Habana, donde tocaba el órgano de Jesús de Miramar, dedicándose casi en exclusiva a la composición musical religiosa, entre cuya producción destacan varias misas.

12 Cfr.: Ondarra, Lorenzo: "San Sebastián, José Antonio de [José Gonzalo Zualaika y Arregui, padre Donostia]", en Diccionario de la Música Española e Hispanoamericana. Vol.9. Madrid, Sociedad General de Autores y Editores, 2002, pp.657662.

13 Fue asesinado durante la Guerra Civil española. Entre sus abundantes zarzuelas, en general de música dulce y alegre, y en ocasiones, ya sentimental, ya enérgica, destacan la cómica Los reclutas, Las elecciones, Trapacerías, El zapatero dentista, o Bemol o maestro de capilla (en un acto). 
"SEIS / SONATAS / para Clave y Piano Fuerte / DEDICADAS / A la R L. SociedAd BASCONGADA / COMPVESTAS / Por D. Joachín Montero / Organista en la Parroquía, de / $S^{\text {n}}$. Pedro el R'. de / Sevilla. / Obra 1'. Precio $26 \mathrm{P}^{\text {.". }}$

De este compositor y organista, de quien "se sabe muy poco de su vida"14, y más concretamente, sobre sus sonatas para clave y fortepiano Opus 1, se afirmaba, hasta hace muy poco tiempo, que se hallaban “en una publicación cuyo único ejemplar figura en la Biblioteca del Orfeó Català”15. Afortunadamente, la reciente aparición del presente impreso en el mexicano archivo de Celaya, no sólo desdice dicha afirmación, sino que testimonia la difusión que dicha obra tuvo en territorio americano, en un claro ejemplo de circulación editorial de música a ambos lados del Atlántico ${ }^{16}$.

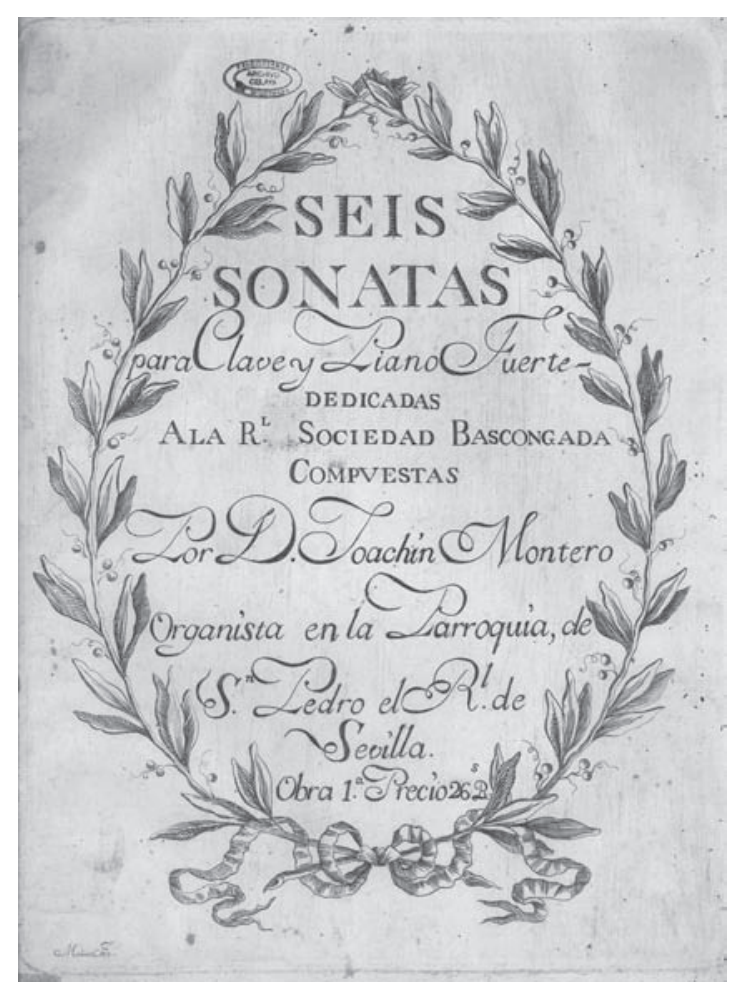

Figura 15. Portada de un ejemplar impreso con las sonatas "para clave y piano fuerte" de Joaquín Montero. (Madrid, s.e., Molina grabador [Sevilla], 1790c).

14 Ruiz Tarazona, Andrés: "Montero, Joaquín”, en Diccionario de la Música Española e Hispanoamericana. Vol.7. Madrid, Sociedad General de Autores y Editores, 2000, p.714.

15 Ibídem.

16 (Agradezco estas informaciones al Dr. Antonio Ezquerro). Estas Sonatas las ejecuté por primera vez en la ciudad de Lima (Perú), en un concierto en el Centro Cultural de España, año de 2009. 
Su autor, Joaquín Montero (*1740c; $f .1764 ; \nmid 1815 p)$, organista en Sevilla en un tiempo en el que desarrollaban su actividad en dicha ciudad andaluza músicos tan destacados como Antonio Ripa (*Tarazona, Zaragoza, 1721; †Sevilla, 1795) -maestro de capilla de la catedral hispalense desde 1768 hasta su muerte- o Manuel Blasco de Nebra (*Sevilla, 1750; †Ibídem, 1784) -notable autor de música de tecla-, trabajó también una colección de minuetos, datados en 1764, que se conservan manuscritos en la Biblioteca Nacional de España en Madrid (E-Mn, M 2810), y que pasan por ser las composiciones para teclado más antiguas en España que señalan específicamente que pueden utilizarse, además de para el clave, para ser tocadas al pianoforte, tal como aparece en su portada ${ }^{17}$.
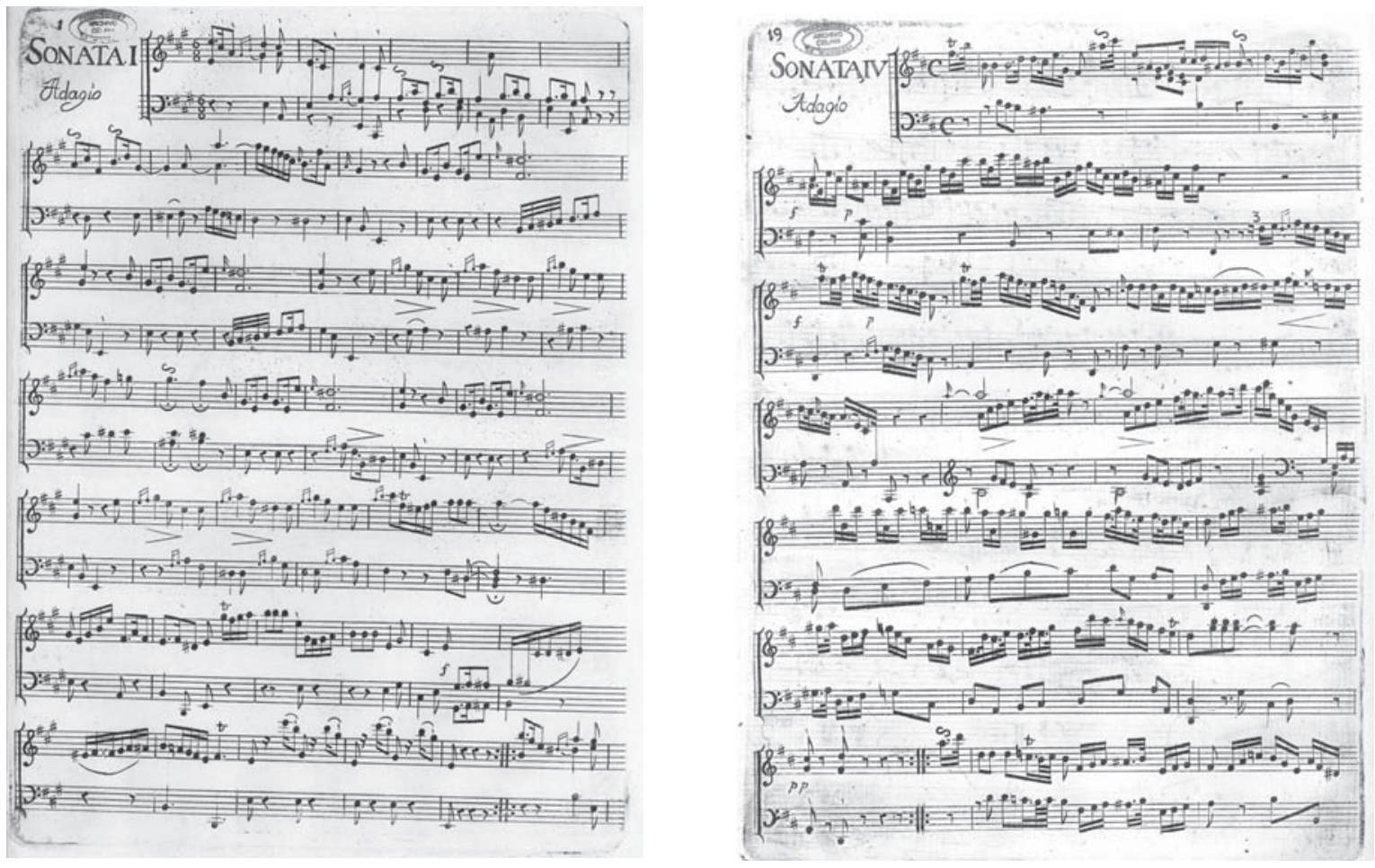

Figura 16. Inicio de dos de las sonatas "para clave y piano fuerte" de Joaquín Montero.

Sonata I, p.1, y Sonata IV, p.19.

17 Existe edición: RuIz Pipó, Antonio: Joaquín Montero. Diez minuetos. Madrid, Unión Musical Española, 1973. Vid. también: Powell, Linton: "Montero, Joaquín”, en The New Grove Dictionary of Music and Musicians. Vol.12. Londres, Macmillan, 1980, p.512. El manuscrito en cuestión de la Biblioteca Nacional recoge Música de salterio, clave y orquesta, anónima, en un volumen con 77 folios de música, copia e varias manos y encuadernación de la época en pergamino. En su fol.1 se indica "Joan Roig y Posas, Comercian en Bar ${ }^{\text {na }}$ 1764". En el fol.32 se puede leer: "Siguese 12 Minuetes para Clave y Piano Fuerte, compuestos por D. Joaquin Montero", aunque solamente hay diez minuetes. (Vid.: -Anglés, Higinio; y SuBIRÁ, José: Catálogo Musical de la Biblioteca Nacional de Madrid I. Manuscritos. Barcelona, Instituto Español de Musicología, csic, 1946, pp.336-339). Otros datos en: -SALDONI, Baltasar: DiccionarioBiográfico-Bibliográfico de Efemérides de Músicos Españoles. Tomo IV. Madrid, Antonio Pérez Dubrull, 1881, pp.215-216. 
Publicó sus Seis Sonatas... el 24.12.1790 en Madrid, aunque las grabó en Sevilla ${ }^{18}$, el mismo año en que, precisamente, iba a editar también (el 16.07.1790) un tratado teórico-musical titulado Compendio armónico que contiene las definiciones de las quatro partes en que se divide la musica, sacado de los autores mas antiguos ${ }^{19}$. Se sabe, además, que el 28.10 .1796 publicó asimismo otras composiciones (minués y sonatas) para clave, y que en 1815 trabajó un Tratado teórico-práctico sobre el contrapunto, que ha quedado manuscrito, y que se halla en la barcelonesa Biblioteca de Catalunya, así como en la Biblioteca Colombina de la catedral de Sevilla.

Las presentes Seis Sonatas..., se consideran sus obras de mayor calidad y se conocen hoy gracias a una única edición en tiempos modernos ${ }^{20}$.

No es de sorprender demasiado el que estas Sonatas se encuentren en Celaya, donde existió desde su fundación una Real Sociedad Bascongada.

Termino entonces aquí, esperando más sorpresas en lo que aún queda por catalogar del Archivo Musical del Convento de San Francisco de Celaya, Guanajuato.

Recibido: 08/03/2010

Aceptado: 15/04/2010

18 Álvarez Cañibano, Antonio: “Sevilla. il. Música Profana”, en Diccionario de la Música Española e Hispanoamericana. Vol.9. Madrid, Sociedad General de Autores y Editores, 2002, p.984.

19 Este volumen, de 62 páginas, en $8^{\circ}$, fue publicado en Sevilla, por Vázquez e Hidalgo, en 1790. Se conocen tres ejemplares conservados, uno de ellos en España (en la Biblioteca de Catalunya, en Barcelona), y dos en los Estados Unidos de América (en la Biblioteca Newberry de Chicago, Illinois, y en la Biblioteca de la Escuela de Música de la Universidad de Yale, New Haven, Connecticut, respectivamente). pañola, 1977.

20 Powell, Linton (ed.): Joaquín Montero. Seis sonatas para clave y fuerte piano, Op. 1. Madrid, Unión Musical Es- 
